\title{
Survival from childhood cancer in northern England, 1968-2005
}

\author{
NO Basta', PW James', B Gomez-Pozo', AW Craft ${ }^{2}$ and RJQ McNally*,I \\ 'Institute of Health and Society, Newcastle University, Sir James Spence Institute, Royal Victoria Infirmary, Newcastle upon Tyne NEI 4LP, England, UK; \\ ${ }^{2}$ Northern Institute of Cancer Research, Newcastle University, Sir James Spence Institute, Royal Victoria Infirmary, Newcastle upon Tyne NEI 4LP, \\ England, UK
}

BACKGROUND: Cancer is the second most common cause of death in children in the developed world. The study investigated patterns and trends in survival from childhood cancer in patients from northern England diagnosed 1968-2005.

METHODS: Five-year survival was analysed using Kaplan-Meier estimation for four successive time periods. Cox regression analysis was used to explore associations with age and demographic factors.

RESULTS: The study included 2958 cases ( 1659 males and 1299 females). Five-year survival for all cancers improved significantly from $39 \%$ in $1968-1977$ to $79 \%$ in $1998-2005(P<0.001)$. Five-year survival for leukaemia increased from $24 \%$ to $81 \%(P<0.00 I)$, lymphoma from $46 \%$ to $87 \%(P<0.001)$, central nervous system tumours from $43 \%$ to $73 \%(P<0.00$ I $)$, bone tumours from $21 \%$ to $75 \%(P<0.00 \mathrm{I})$, soft tissue sarcoma from $30 \%$ to $58 \%(P<0.00 \mathrm{I})$ and germ cell tumours from $59 \%$ to $97 \%(P<0.00 \mathrm{I})$. Survival was worse for cases of acute lymphoblastic leukaemia $(P<0.00 I)$ and astrocytoma $(P<0.00 I)$ aged $10-14$ years compared with $0-4$-year olds.

CONCLUSION: There were marked improvements in survival over a 38-year time span. Future work should examine factors that could influence further improvement in survival such as diagnosis delays.

British Journal of Cancer (201 I) I 05, |402- |408. doi:10.1038/bjc.201 I.34 I www.bjcancer.com

Published online 20 September 2011

(c) 20II Cancer Research UK

Keywords: childhood cancer; survival; leukaemia; lymphoma; solid tumours

Cancer is the second most common cause of death in children, aged 0-14 years, in the developed world. The continuous improvement in diagnostic and treatment strategies for cancer has led to significant improvements in survival for a wide range of childhood cancers (Kaatsch, 2010). Survival from childhood cancer in the United Kingdom has been included in international comparisons since the start of the European Cancer Registrybased Study on Survival and Care of Cancer Patients (EUROCARE) and the Automated Childhood Cancer Information System project (ACCIS) studies (Coebergh et al, 2001; Steliarova-Foucher et al, 2004; Pritchard-Jones et al, 2006; Gatta et al, 2009). Five-year survival for all European childhood cancers diagnosed during 1995-2002 was 81\% (Gatta et al, 2009). Survival from childhood cancer in Great Britain (GB) improved substantially between 1971 and 1985 with 5 -year survival reaching $76 \%$ for all cancer cases diagnosed during 1980-1991 (Stiller and Bunch, 1990; Stiller, 1994). A previous study from the Northern Region of England has examined survival in children and young adults diagnosed during the period 1968-1995 and reported significant improvements (Cotterill et al, 2000).

Population-based cancer registry data are regarded as highly reliable for comparison and analysis of survival (Pritchard-Jones and Stiller, 2007).

The aim of the present study was to investigate survival for cancer in children (aged 0-14 years) diagnosed during the period 1968-2005, and registered by the population-based Northern

*Correspondence: Dr RJQ McNally; E-mail: Richard.McNally@ncl.ac.uk Received 4 January 20 I ; revised 22 July 201 I; accepted 8 August 201 I; published online 20 September 2011
Region Young Persons' Malignant Disease Registry (NRYPMDR). The study examined patterns and trends in survival, updating the previously published analysis and also presents separate diagnostic- and gender-specific results.

\section{MATERIALS AND METHODS}

All cases aged 0-14 years diagnosed with a primary malignancy during the period 1968-2005 were obtained from the NRYPMDR. The NRYPMDR is a specialist registry, established in 1968, covering the counties of Northumberland, Tyne and Wear, Durham, Teesside and Cumbria (excluding Barrow-in-Furness). All cases of cancer in the region, diagnosed in 0-24-year olds, are notified to the registry. Cases are identified from multiple sources. Consultants throughout the region notify the registry of any malignancies in this age group. Data are periodically crosschecked with regional and national cancer registries. The registry has a high level of overall completeness and ascertainment, estimated to be $>98 \%$, with a very small proportion of cases lost to follow-up ( $<1 \%$ over the entire study period). Follow-up was achieved by regular checking of death certificates and hospital admission data (Cotterill et al, 2000). Previously registry data were grouped according to a modified version of the International Classification of Diseases for Oncology (ICDO-2; Kramárová et al, 1996) and modifications are documented by Cotterill et al (2000). The International Classification of Childhood Cancer third edition (ICCC-3) for coding morphology and primary site of diagnosis is now followed (Steliarova-Foucher et al, 2005). Following the ICCC third edition, benign and uncertain behaviour neoplasms of intracranial and intraspinal sites are included in both the central 
nervous system (CNS) tumour and the non-gonadal germ cell tumours groups. Myelodysplastic syndrome and other myeloprofilerative diseases are included under the subgroup 'other leukaemia'.

\section{Statistical analysis}

Survival at 5 years was analysed using Kaplan-Meier estimation, for each diagnostic group, within four successive subperiods 1968-1977, 1978-1987, 1988-1997 and 1998-2005 (Kaplan and Meier, 1958). Unadjusted trends in survival for each diagnostic group were assessed using log rank tests. The end point of interest was death from any cause, with date of diagnosis taken to be the time of origin. The NRYPMDR attempts to obtain comprehensive long-term follow-up on all childhood patients and was mostly complete until 31 December 2008.

Cox Proportional hazards regression analysis was used to model the probability of survival in relation to age at diagnosis $(0-4,5-9$ and 10-14 years), gender, subperiods of diagnosis (1968-1977, 1978-1987, 1988-1997 and 1998-2005), area-level socioeconomic deprivation quintiles and area-level population density for all diagnostic groups and subgroups with $>45$ cases for the entire follow-up period. The significance of each covariate in the model was assessed using the partial likelihood ratio test. Non-nested models were compared using Akaike's Information Criterion (Collett, 2003). Hazard ratios (HRs) of variables were retained in the model only if they contributed significantly to the overall model fit. Simpler models, fitting subperiod of diagnosis and deprivation as continuous variables, were also assessed. The proportional hazards assumption was tested by examining Schoenfeld residuals and only those models that met the assumption were included in the results (Cox, 1972).

Cases were divided into five groups on the basis of the quintile of the distribution of Townsend deprivation score for the census ward of residence, from the most affluent to the most deprived (Townsend et al, 1988). Townsend scores were based on 1971, 1981, 1991 and 2001 censuses estimated for 2001 census ward geography (Norman et al, 2008; Norman, 2010). Population density for each electoral ward was calculated by dividing the population by the area. Wards were classified according to tertile of population density (for the period 1968-1985: low population density 2-1103 persons per $\mathrm{km}^{2}$, medium population density $1118-3290$ persons per $\mathrm{km}^{2}$, high population density $3300-11357$ persons per $\mathrm{km}^{2}$; for the period 1986-1995: low 2-1052 persons per $\mathrm{km}^{2}$, medium $1058-3094$ persons per $\mathrm{km}^{2}$, high $3113-10680$ persons per $\mathrm{km}^{2}$; and for the period 1996-2005: low 2-978 persons per $\mathrm{km}^{2}$, medium $981-2933$ persons per $\mathrm{km}^{2}$, high $2974-$ 8882 persons per $\mathrm{km}^{2}$ ). The ward population density figures for the periods 1968-1985, 1986-1995 and 1996-2005 were based, respectively, on the 1981, 1991 and 2001 censuses estimated for 2001 census ward geography. Statistical significance was taken to be $P<0.05$ in all analyses. Stata version 10 was used for the statistical analysis.

\section{RESULTS}

The study included a total of 2958 childhood cancer cases, diagnosed during the period 1968-2005 (1659 males and 1299 females). Five-year survival by period of diagnosis, for the diagnostic groups and subgroups is given in Table 1 and for males and females in Tables 2 and 3, respectively. Survival increased significantly over the study period $(P<0.001)$ from a 5 year rate of $39 \%$ for the subperiod $1968-1977$ to $60 \%$ for 1978 1987, 75\% for $1988-1997$ and $79 \%$ for $1998-2005$ (Figure 1A). For all leukaemia and lymphoma combined survival increased from $29 \%$ to $60 \%, 78 \%$ and $83 \%$ for the four subperiods, respectively $(P<0.001)$. Similarly, survival for solid tumours increased from
$45 \%$ to $59 \%, 72 \%$ and $77 \%$, respectively $(P<0.001)$. Cox modelling showed there was little or no evidence of gender differences for survival among any of the specific diagnostic groups except for Hodgkin lymphoma (HL), where gender contributed significantly to the final model. Including subperiod of diagnosis, as a continuous variable, instead of a categorical variable, significantly improved the model fits for survival of several groups and subgroups of cancer (Table 1). It also showed that the apparent drop in survival for some diagnoses in the fourth time period compared with the third time period was not statistically significant. There was a steady increase in survival for ependymoma $(P=0.02)$, osteosarcomas $(P<0.001)$, soft tissue sarcoma $(P<0.001)$ and rhabdomyosarcoma $(P=0.001)$. There was also no evidence for an effect of area-level residential population density on survival so it was dropped from all final models.

\section{Leukaemia}

There was a significant increase in survival for all leukaemias and specifically for acute lymphoblastic leukaemia (ALL; Figures 1B and C). Five-year survival for ALL increased from $30 \%$ in the first subperiod to $62 \%, 78 \%$ and $82 \%$ in the second, third and fourth subperiods, respectively $(P<0.001)$. Cox regression modelling for ALL cases showed that age at diagnosis and categorical period of diagnosis were significant in the final model $(P<0.001)$. After adjustment for period of diagnosis, the risk of death was higher for 10 - 14-year olds compared with those aged $0-9$ years $(\mathrm{HR}=1.76$; $95 \% \mathrm{CI}=1.35-2.30)$. Survival for acute non-lymphocytic leukaemia (ANLL) was very low in the earlier half of the study but improved markedly during the latter half with a significantly large increase from $14 \%$ in $1978-1987$ to $78 \%$ in $1988-1997$ and $77 \%$ in $1998-2005(P<0.001)$.

\section{Lymphoma}

Survival improved significantly over the study period for all lymphomas $(P<0.001$; Figure 1D). Survival for HL improved over the study period $(P=0.003)$ from a high level of $73 \%$ in the first subperiod to $90 \%$ in the second subperiod but with little subsequent improvement. Cox regression modelling for HL cases showed that gender and subperiod of diagnosis as a continuous variable were significant in the final model. After adjustment for period of diagnosis, girls had a higher risk of death compared with boys $(\mathrm{HR}=3.43 ; 95 \% \mathrm{CI}=1.37$; Figure 2 ). There was a marked improvement in 5-year survival for non-Hodgkin lymphoma (NHL) from $23 \%$ to $83 \%$ in the fourth subperiod $(P<0.001)$, as shown by the Cox analysis $(P$ for linearity $<0.001)$.

\section{CNS tumours}

Survival improved significantly over the study period for all cases of CNS tumours combined, with 5-year survival improving from $43 \%$ to $73 \% \quad(P<0.001$; Figure $1 \mathrm{E})$. There were significant improvements in survival for ependymoma from $39 \%$ to $69 \%$ $(P=0.013)$ and for astrocytoma from $60 \%$ to $77 \%(P=0.049)$, but the apparent improvement for primitive neuroectodermal tumours (PNETs) from $24 \%$ to $63 \%$ was not significant $(P=0.236)$.

For cases of PNET, Cox regression modelling showed that age at diagnosis and quintile of deprivation as a categorical variable were significant in the final model, but subperiod of diagnosis was not significant. Survival was significantly better in the areas with highest deprivation $(\mathrm{HR}=0.10 ; 95 \% \mathrm{CI}=0.03-0.32)$, and better for older children aged 5-9 compared with those aged 0-4 years $(\mathrm{HR}=0.33 ; 95 \% \mathrm{CI}=0.18-0.61)$ and also better for children aged $10-14$ years although this was not significant $(\mathrm{HR}=0.58 ; 95 \%$ $\mathrm{CI}=0.31-1.08)$.

For ependymoma cases, the final model included subperiod of diagnosis and deprivation as continuous variables. Survival for 
Table I Percentage 5-year survival by time period and diagnostic group

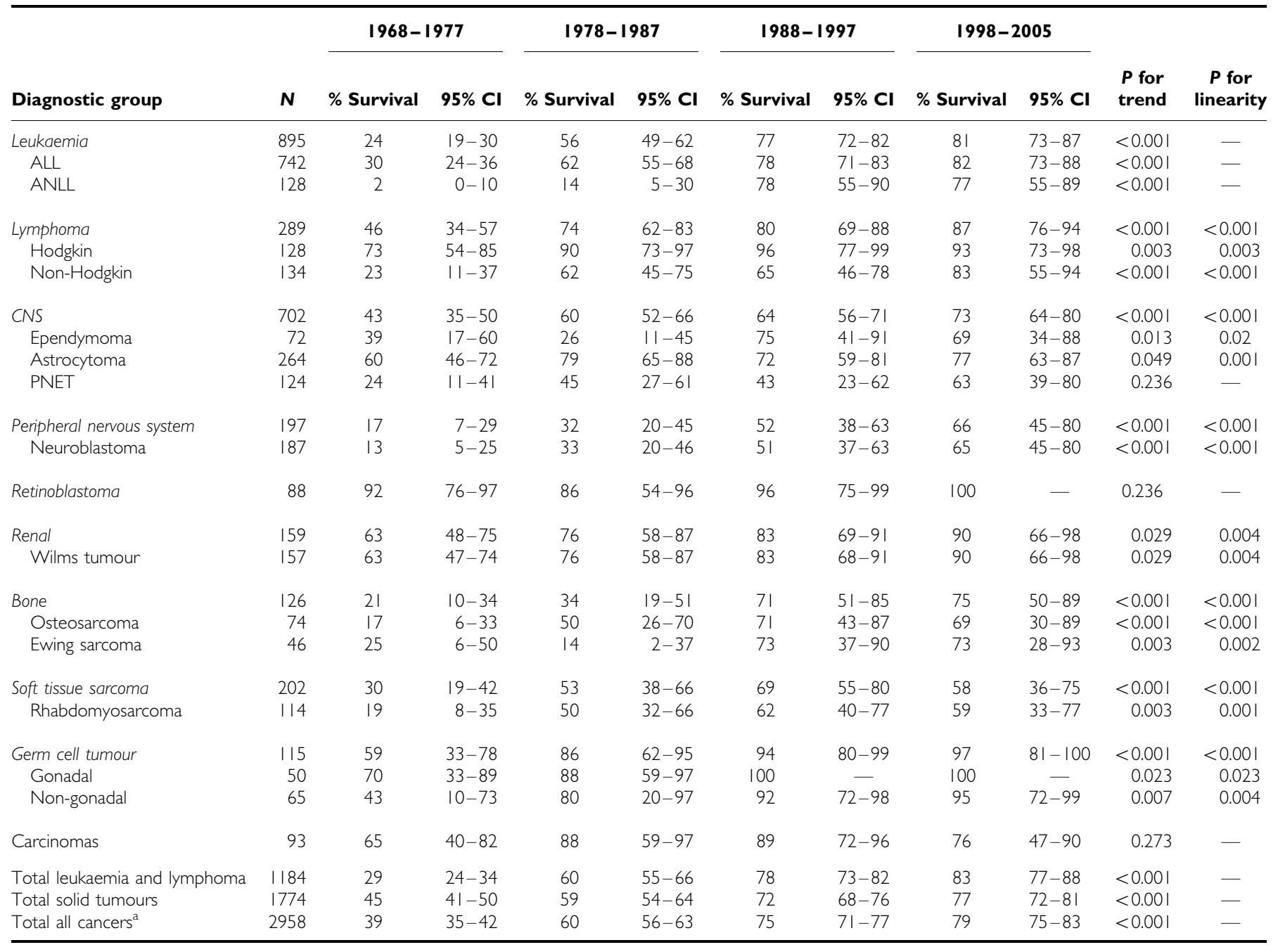

Abbreviations: $\mathrm{Cl}=$ confidence intervals; $\mathrm{ALL}=$ acute lymphoblastic leukaemia; $\mathrm{ANLL}=$ acute non-lymphocytic leukaemia; $\mathrm{CNS}=$ central nervous system; PNET = primitive neuroectodermal tumour. Table shows all diagnostic groups with $>45$ patients diagnosed over the study period. ${ }^{a}$ Total including other miscellaneous groups.

ependymoma cases was better as deprivation got worse with HR decreasing by a factor of $0.77(95 \% \mathrm{CI}=0.62-0.97)$ for each quintile of deprivation.

For astrocytoma cases, the final model included age at diagnosis, subperiod of diagnosis as a continuous variable and quintile of deprivation as a categorical variable. Survival for astrocytoma cases was better in the areas with the highest deprivation $(\mathrm{HR}=0.36 ; 95 \% \mathrm{CI}=0.16-0.80)$. However, survival was significantly poorer for children aged $10-14$ years $(\mathrm{HR}=2.51 ; 95 \%$ $\mathrm{CI}=1.37-4.62$ ).

\section{Peripheral nervous system tumours}

There was a significant increase in overall survival for neuroblastoma from $13 \%$ to $65 \%(P<0.001)$.

\section{Retinoblastoma}

Survival was consistently high and between 86 and $100 \%$ with no significant variation $(P=0.236)$.

\section{Renal tumours}

There was a significant increase in the overall survival for Wilms tumour $(P=0.029)$.

\section{Bone tumours}

Overall survival for bone tumours significantly increased from $21 \%$ to $75 \% \quad(P<0.001)$. Cox regression showed that the improvement in survival for both osteosarcoma and Ewing Sarcoma was steady $(P<0.001)$ and the apparent drop from $71 \%$ in the third period to $69 \%$ in the fourth period was most likely due to random sampling variation due to small numbers.

\section{Soft tissue sarcomas}

Survival significantly increased for all soft tissue sarcoma from $30 \%$ to $58 \%(P=0.001)$ and specifically for rhabdomyosarcoma from $19 \%$ to $59 \%(P=0.003)$. Cox regression showed that the improvement in survival for rhabdomyosarcoma was steady $(P=0.001)$ and the apparent drop from $62 \%$ in the third period to $59 \%$ in the fourth period was most likely due to random sampling variation.

\section{Germ cell tumours}

Five-year survival for all gonadal germ cell tumours significantly improved from $70 \%$ to $100 \%(P=0.023)$. For all non-gonadal germ cell tumours, there was a significant increase in 5-year survival from $43 \%$ to $95 \%(P=0.007)$. 
Table 2 Percentage 5-year survival by time period and diagnostic group for males

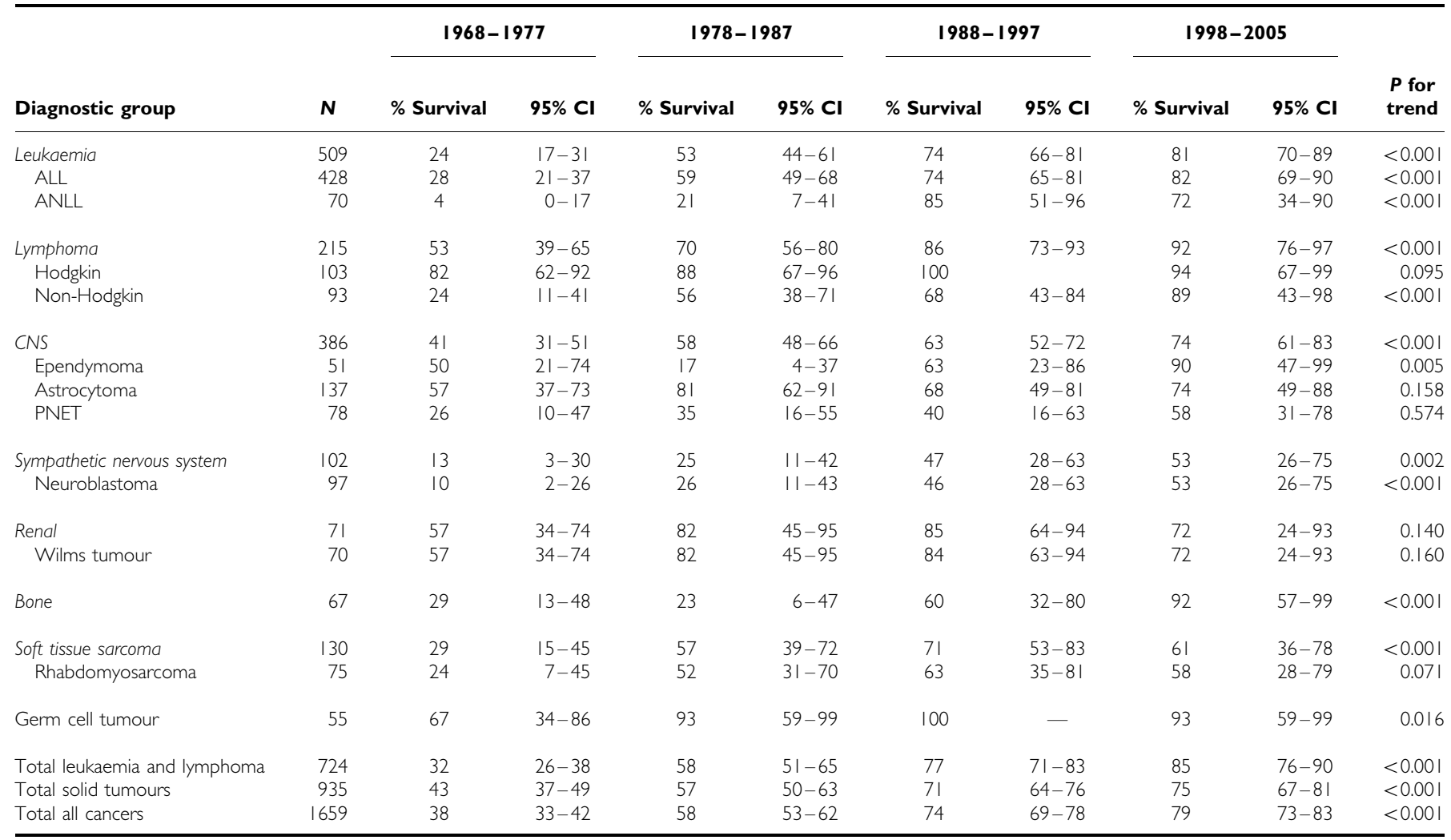

Abbreviations: $\mathrm{Cl}=$ confidence intervals; $\mathrm{ALL}=$ acute lymphoblastic leukaemia; $\mathrm{ANLL}=$ acute non-lymphocytic leukaemia; $\mathrm{CNS}=$ central nervous system; PNET = primitive neuroectodermal tumour. Table shows all diagnostic groups with $>45$ patients diagnosed over the study period.

Table 3 Percentage 5-year survival by time period and diagnostic group for females

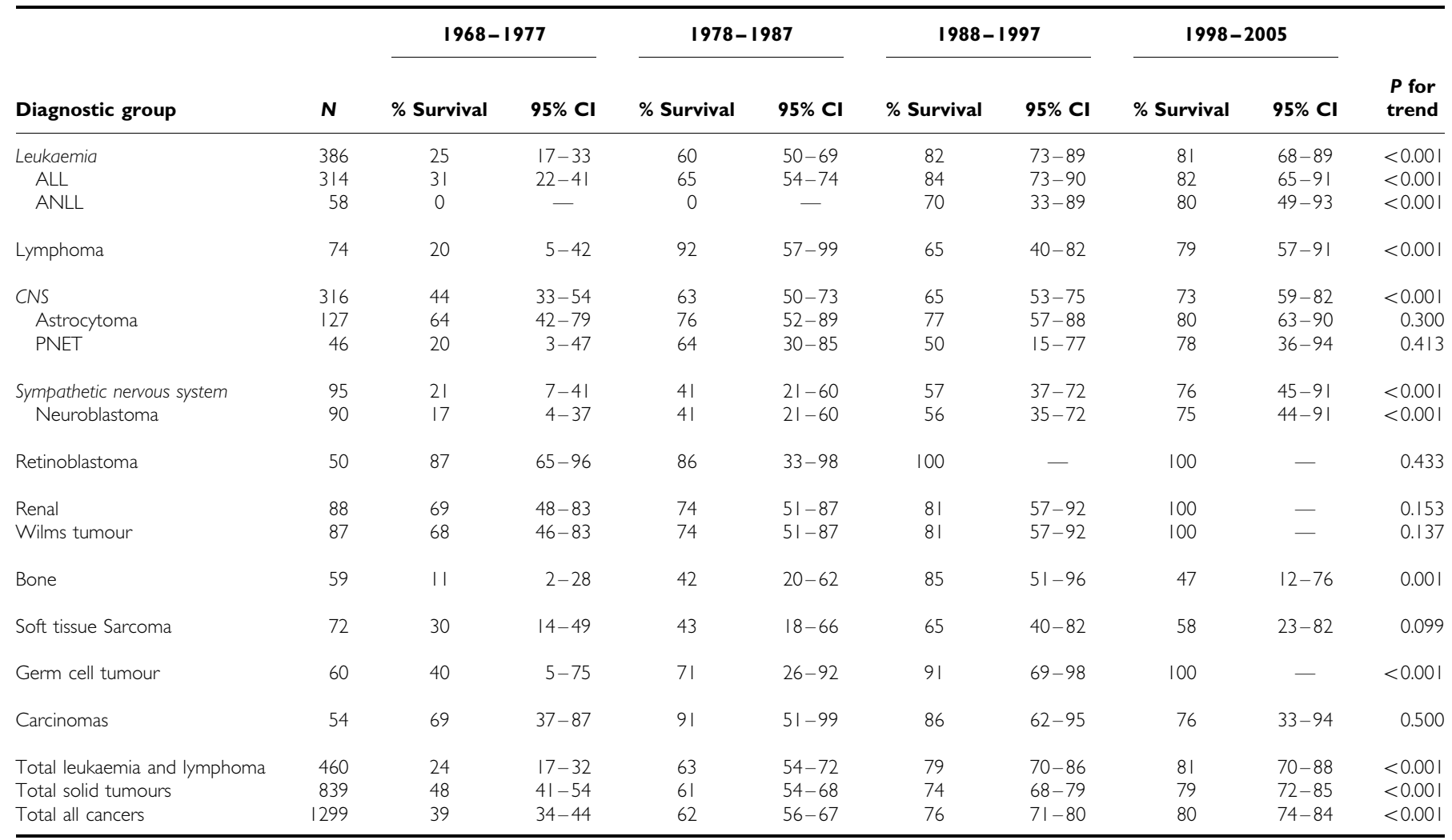

Abbreviations: $\mathrm{Cl}=$ confidence intervals; $\mathrm{ALL}=$ acute lymphoblastic leukaemia; $\mathrm{ANLL}=$ acute non-lymphocytic leukaemia; $C N S=$ central nervous system; PNET = primitive neuroectodermal tumour. Table shows all diagnostic groups with $>45$ patients diagnosed over the study period. 

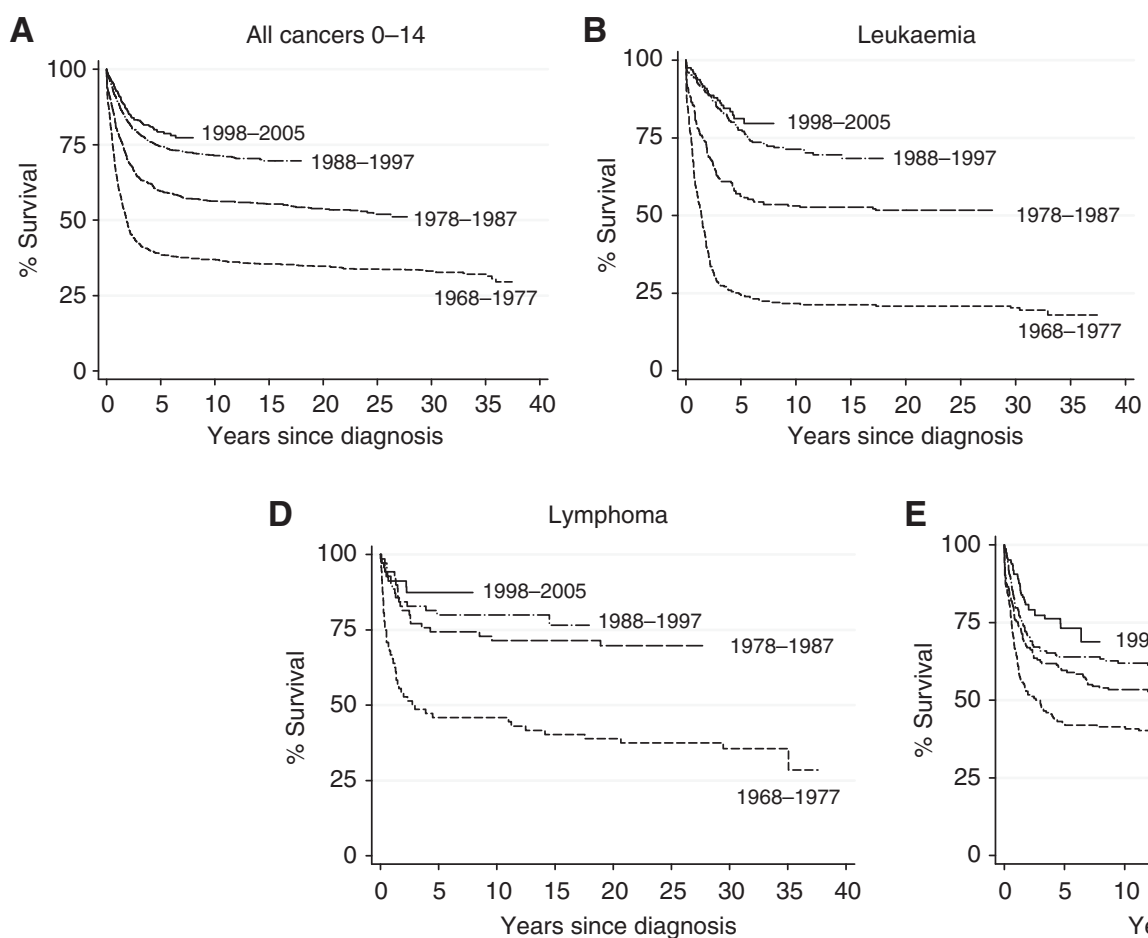

Figure I Kaplan-Meier survival plots. (A) All cancers 0-14, (B) leukaemia,

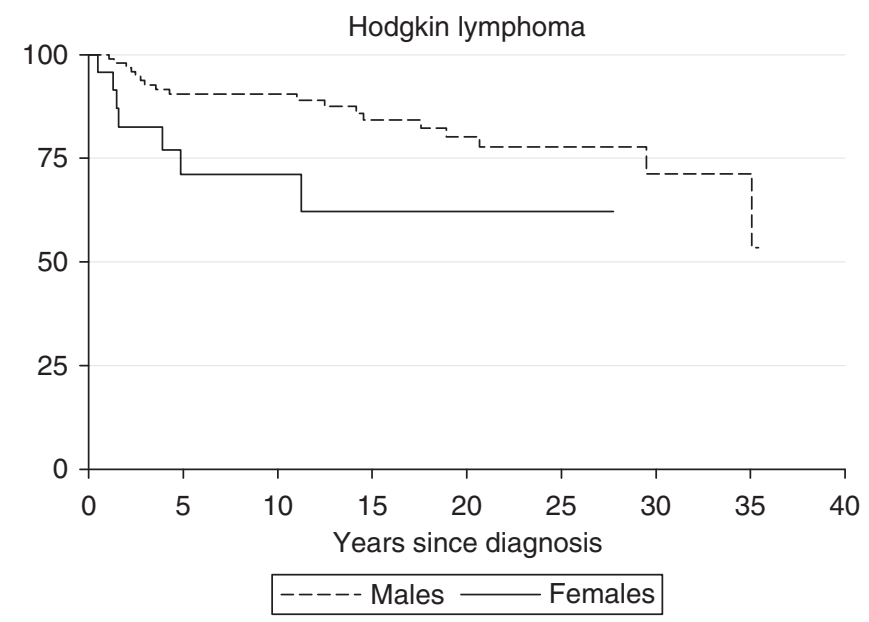

Figure 2 Kaplan-Meier survival plot by gender.

\section{Carcinomas}

The apparent increase in survival for carcinomas was not statistically significant $(P=0.273)$.

\section{DISCUSSION}

This study provides up-to-date estimates of childhood cancer survival from a population-based cancer registry in northern England. The population of the Northern Region is ethnically homogenous with fewer than $2 \%$ from ethnic minorities (Office of Population Censuses and Surveys Census Division, General Register Office (Scotland) Census Branch, 1983; Office for National Statistics, 1991, 2001). The incidence of childhood cancer in this
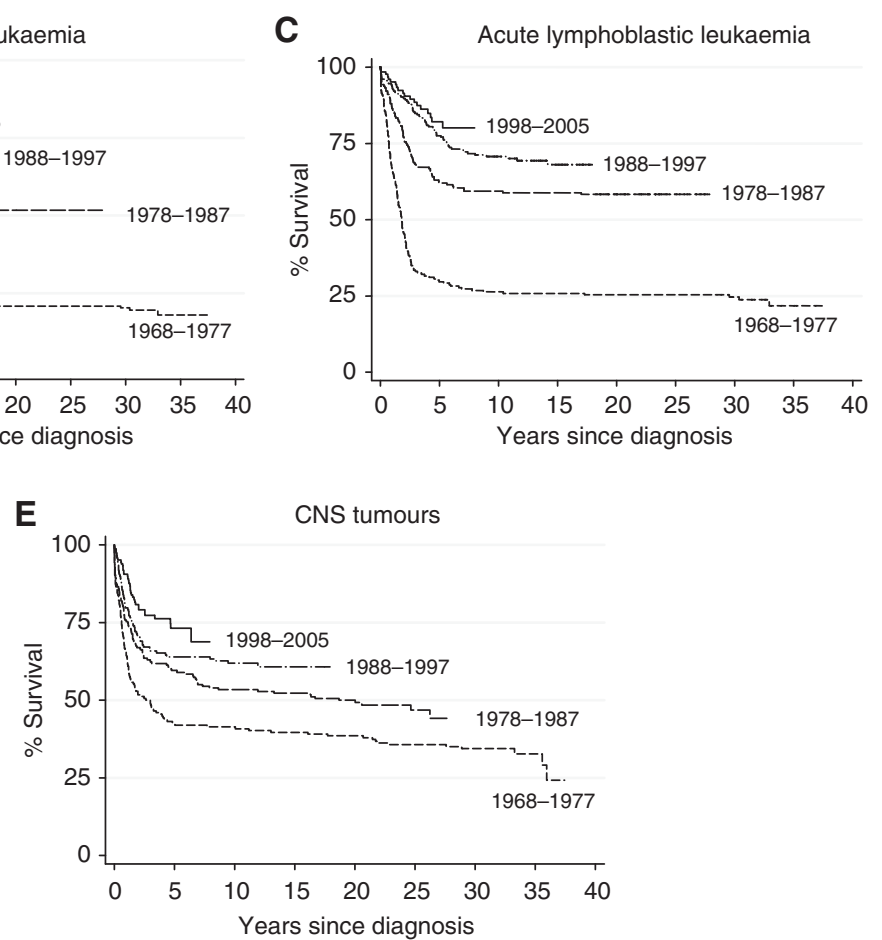

(C) acute lymphoblastic leukaemia, (D) lymphoma, and (E) CNS tumours.

area is similar to England in general (Magnanti et al, 2008a, b). Five-year survival for all cancer in children (aged $0-14$ years) have improved considerably over the study period. The largest improvements in survival in more recent years were seen for ANLL (from the third subperiod) and for NHL and sympathetic nervous system tumours (especially in the last subperiod). However, the new data showed continued improvements in survival for the groups comprising all cancers, all haematological malignancies and all solid tumours since the previously published report (Cotterill et al, 2000). The previously published study only reported survival for all cancers, haematological malignancies and solid tumours collectively; in the present study, we report both diagnostic- and gender-specific survival.

The improvement in overall cancer survival during the study period is consistent with other studies. The overall 5-year survival from cancer was similar to a previous report from the whole of the United Kingdom where the 5-year survival for the period $1991-2000$ was $75 \%$ (Stiller, 2007). Our findings were also similar to those reported by other studies, including the EUROCARE study (5-year survival for all childhood cancers combined, diagnosed 1995-2002: 81\%; Gatta et al, 2009), the Surveillance, Epidemiology and End Results (SEERs) programme in the United States (cases diagnosed 1999-2006: 79.9\%; Altekruse et al, 2010) and from Australia (cases diagnosed 1997-2006: 79.5\%; Baade et al, 2010). For specific diagnostic subgroups, similar findings were also reported. Childhood cancer survival figures reported from the SEER and the Australian studies were produced using relative survival. However, the results from the EUROCARE study were observed survival. Using relative survival makes little difference to the estimates because deaths due to other causes are rare in children (Gatta et al, 2009).

In GB, the 5-year survival for ALL, HL and NHL diagnosed during 1991-2000 was $87 \%, 95 \%$ and $79 \%$, respectively (Stiller, 2007); and for all European children, diagnosed in 1995-2002 were $85 \%, 95 \%$ and $82 \%$ (Gatta et al, 2009). Since the greatest improvements in survival for leukaemia in early 1990s there have been very little subsequent improvements. 
The 5-year survival for ANLL has seen great improvements for children diagnosed 1987-2005 (77\%) and the reason for this improvement was likely to be due to additional more intensive therapy protocols that were introduced by the United Kingdom Medical Research Council (UK MRC) trials in early 1980s (Gibson et al, 2005). These protocols have been followed in the treatment centres in the northern region. The 5-year overall survival for children with ANLL who were treated on UK MRC trials between 1988 and 2002 was 66\% (Gibson et al, 2005) and for ANLL cases diagnosed 1996-2000 in GB was 65\% (Stiller, 2007).

The overall 5-year survival results for CNS tumours showed significant improvements and there were non-significant improvements for PNETs. CNS tumours are a very heterogeneous diagnostic group. Five-year survival from the United Kingdom, for cases diagnosed during $1991-2000$ was $69 \%, 66 \%$ and $79 \%$ for all CNS tumours, ependymoma and astrocytoma, respectively (Stiller, 2007). Five-year survival for astrocytoma diagnosed 1995-2005 reported for Europe (78\%) (Gatta et al, 2009) was similar to the present study $(77 \%)$, but the 5-year survival for astrocytoma diagnosed during 1999-2006 reported in the United States by the SEER programme (Altekruse et al, 2010) was higher $(84.8 \%)$, although the same ICCC-3 classification of coding morphology was followed by the three studies (SteliarovaFoucher et al, 2005). Survival for PNETs reported in the current study $(63 \%)$ is similar to that reported from the EUROCARE study for embryonal CNS tumours (which were mainly medulloblastoma and PNET) diagnosed during 1995-2002 (66\%) (Gatta et al, 2009).

For peripheral nervous system tumours, which comprise mainly neuroblastoma, we found recent marked increases in the 5-year survival especially in the last subperiod. An increase in survival for neuroblastoma cases diagnosed in the United Kingdom was persistent over the time period, with the greatest increases in survival from 1971-1975 to 1981 - 1985 with little change in 19861990 but then followed by a further increase in 1996-2000 (Stiller, 2007). Our results show that the 5-year survival for neuroblastoma in the last subperiod was $65 \%$, which is higher than the 5 -year survival reported from the whole of United Kingdom, for cases diagnosed 1991-2000 (59\%) (Stiller, 2007), but lower than reported from Europe (72\%) (Gatta et al, 2009) and the United States (73\%) (Altekruse et al, 2010).

The overall 5-year survival for bone tumours diagnosed during 1998-2005 (75\%; osteosarcomas: 69\%; Ewing tumours: 73\%) was higher than that reported from the earlier study from Northern England and the West Midlands for cases diagnosed 1981-2000 where overall 5-year survival for the period 1995-2000 was $62 \%$ (osteosarcomas: 57\% and Ewing sarcoma: 70\%; Eyre et al, 2009).

Soft tissue sarcoma had the lowest 5-year survival of all diagnostic groups (58\%) which is lower than rates reported from the United Kingdom for cases diagnosed 1991-2000 (66\%; Stiller, 2007). Germ cell tumours had the highest 5 -year survival and this was similar to previous reports from the United Kingdom (Stiller, 2007) and from Europe (Gatta et al, 2009).

The Cox regression analyses showed that survival for ALL and astrocytoma was influenced by age of the patients, with older children faring worse. Our data are consistent with findings from the whole of the United Kingdom for ALL and astrocytoma where older children aged 5-14 years had worse prognosis than children aged 1-4 years (Stiller, 2007). The age at which children are diagnosed with cancer is an important prognostic factor for several childhood cancers, which may be used in several classifications of high risk patients and stratification for treatment (Coebergh et al, 2001). Children diagnosed with ALL, who were patients in the UK MRC clinical trials protocols between 1980 and 2001, and who were older than 10 years were consistently associated with high risk disease and worse outcome compared with children younger than 10 years (Mitchell et al, 2010). Also, the delay in access to care among adolescents diagnosed with cancer may contribute to worse survival for older children (Albritton and Eden, 2008). Survival from ALL is reported to be worse in adolescent groups compared with younger patients (Feltbower et al, 2009).

There were no significant differences in survival for any of the cancer types by area-level socioeconomic deprivation except for CNS tumours where survival was better for children resident in more deprived areas compared with those from more affluent areas. A similar unexpected association between poorer survival and higher affluence was previously reported for children and young adults diagnosed with CNS tumours in Yorkshire (Feltbower et al, 2004). These findings were in contrast to the data from England and Wales. Coleman et al (1999) have shown that deprivation has a strong influence on cancer survival rates in adults, but much less influence in children. The findings of the present study may reflect the fact that more deprived areas are mostly constituted of urban areas which could have closer geographic access to diagnostic and treatment services. However, these findings should be interpreted with caution and the role of chance cannot be ruled out. We found little evidence of difference in survival between the sexes, apart for HL which was based on a small number of girls. Previous studies have found evidence of sexspecific differences in survival for ALL (Coebergh et al, 2001; Stiller, 2007; Johnston et al, 2010). Johnston et al (2010) also report less favourable outcomes for neuroblastoma in boys than in girls .

In conclusion, our results indicate that there has been substantial improvement in survival for childhood cancer in the North of England over the last four decades. This is resulting in a growing population of long-term survivors who need long-term follow-up and catering for their needs to minimise morbidity, prevent secondary cancer and to normalise their lives. Improvements in survival may generally be attributed to a number of changes in the management and treatment of childhood cancers. Future work should analyse geographical patterning in cancer survival and other factors that may lead to delays in diagnosis (Richards, 2009).

\section{ACKNOWLEDGEMENTS}

We thank the North of England Children's Cancer Research Fund for financial support. The Northern Region Young Persons' Malignant Disease Registry is funded by the Newcastle Hospitals NHS Trust.

\section{REFERENCES}

Albritton KH, Eden T (2008) Access to care. Pediatr Blood Cancer 50: $1094-1098$

Altekruse SF, Kosary CL, Krapcho M, Neyman N, Aminou R, Waldron W, Ruhl J, Howlader N, Tatalovich Z, Cho H, Mariotto A, Eisner MP, Lewis DR, Cronin K, Chen HS, Feuer EJ, Stinchcomb DG, Edwards BK (eds). (2010) SEER Cancer Statistics Review, 1975-2007. National Cancer Institute: Bethesda, MD
Baade PD, Youlden DR, Valery PC, Hassall T, Ward L, Green AC, Aitken JF (2010) Population-based survival estimates for childhood cancer in Australia during the period 1997-2006. $\mathrm{Br} J$ Cancer 103: $1663-1670$

Coebergh JW, Capocaccia R, Gatta G, Magnani C, Stiller CA (2001) Childhood cancer survival in Europe 1978-92: the EUROCARE study. Eur J Cancer 37: 671-672 
Coleman MP, Babb P, Damiecki P, Grosclaude PC, Honjo S, Jones J, Knerer G, Pitard A, Quinn MJ, Sloggett A, De Stavola BL (1999) Cancer survival trends in England and Wales, 1971 -1995: deprivation and NHS Region. Studies in Medical and Population Subjects No. 61. The Stationery Office: London

Collett D (2003) Modelling Survival Data in Medical Research, 2nd edn, Chapman \& Hall: London

Cotterill SJ, Parker L, Malcolm AJ, Reid M, More L, Craft AW (2000) Incidence and survival for cancer in children and young adults in the North of England, 1968 - 1995: a report from the Northern Region Young Persons' Malignant Disease Registry. Br J Cancer 83: 397 - 403

Cox DR (1972) Regression models and life tables. J R Stat Soc B 34: $187-220$

Eyre R, Feltbower RG, Mubwandarikwa E, Jenkinson HC, Parkes S, Birch JM, Eden TO, James PW, McKinney PA, Pearce MS, McNally RJ (2009) Incidence and survival of childhood bone cancer in northern England and the West Midlands, 1981-2002. Br J Cancer 13: 188-193

Feltbower RG, McNally RJ, Kinsey SE, Lewis IJ, Picton SV, Proctor SJ, Richards M, Shenton G, Skinner R, Stark DP, Vormoor J, Windebank KP, McKinney PA (2009) Epidemiology of leukaemia and lymphoma in children and young adults from the north of England, 1990-2002. Eur J Cancer 45: $420-427$

Feltbower RG, Picton S, Bridges LR, Crooks DA, Glaser AW, McKinney PA (2004) Epidemiology of central nervous system tumors in children and young adults ( $0-29$ years), Yorkshire, United Kingdom. Pediatr Hematol Oncol 21: $647-660$

Gatta G, Zigon G, Capocaccia R, Coebergh JW, Desandes E, Kaatsch P, Pastore G, Peris-Bonet R, Stiller CA; EUROCARE Working Group (2009) Survival of European children and young adults with cancer diagnosed 1995 - 2002. Eur J Cancer 45: 992 - 1005

Gibson BE, Wheatley K, Hann IM, Stevens RF, Webb D, Hills RK, De Graaf SS, Harrison CJ (2005) Treatment strategy and long-term results in paediatric patients treated in consecutive UK AML trials. Leukemia 19: $2130-2138$

Johnston WT, Lightfoot TJ, Simpson J, Roman E (2010) Childhood cancer survival: a report from the United Kingdom Childhood Cancer Study. Cancer Epidemiol 34: 659-666

Kaatsch P (2010) Epidemiology of childhood cancer. Cancer Treat Rev 36: $277-285$

Kaplan ES, Meier P (1958) Nonparametric estimation from incomplete observations. J Am Stat Assoc 53: $457-481$

Kramárová E, Stiller CA, Ferlay J, Parkin DM, Draper GJ, Michaelis J, Neglia J, Qureshi S (1996) International Classification of Childhood Cancer. IARC Technical Report: IARC, Lyon

Magnanti BL, Dorak MT, Parker L, Craft AW, James PW, McNally RJ (2008a) Sex-specific incidence and temporal trends in solid tumours in young people from Northern England, 1968-2005. BMC Cancer 8: 89
Magnanti BL, Dorak MT, Parker L, Craft AW, James PW, McNally RJ (2008b) Sex-specific patterns and trends in the incidence of hematologic malignancies in 0-24 year olds from Northern England, 1968-2005. Haematologica 93: $1438-1440$

Mitchell C, Richards S, Harrison CJ, Eden T (2010) Long-term follow-up of the United Kingdom medical research council protocols for childhood acute lymphoblastic leukaemia, 1980-2001. Leukemia 24: $406-418$

Norman P (2010) Identifying change over time in small area socioeconomic deprivation. Appl Spatial Anal Policy 3: 107-138

Norman P, Simpson L, Sabater A (2008) 'Estimating with Confidence' and hindsight: new UK small-area population estimates for 1991. Popul Space Place 14: $449-472$

Office for National Statistics (1991) Census: Small Area Statistics and Local Base Statistics (computer file) ESRC/JISC Census Programme, Census Dissemination Unit, MIMAS (University of Manchester); 1991

Office for National Statistics (2001) Census: Small Area Statistics and Local Base Statistics (computer file) ESRC/JISC Census Programme, Census Dissemination Unit, MIMAS (University of Manchester); 2001

Office of Population Censuses and Surveys Census Division, General Register Office (Scotland) Census Branch (1983) Census: Small Area Statistics: 100\% Population and Households Aggregated to Ward Level (Great Britain) (computer file) Colchester, Essex, UK Data Archive (distributor). SN, 1893

Pritchard-Jones K, Kaatsch P, Steliarova-Foucher E, Stiller CA, Coebergh JW (2006) Cancer in children and adolescents in Europe: developments over 20 years and future challenges. Eur J Cancer 42: 2183-2190

Pritchard-Jones K, Stiller C (2007) What can we learn from geographical comparisons of childhood cancer survival? Br J Cancer 96: 1493-1497

Richards MA (2009) The National Awareness and Early Diagnosis Initiative in England: assembling the evidence. Br J Cancer 101(Suppl 2): $\mathrm{S} 1-\mathrm{S} 4$

Steliarova-Foucher E, Stiller C, Kaatsch P, Berrino F, Coebergh JW, Lacour B, Parkin M (2004) Geographical patterns and time trends of cancer incidence and survival among children and adolescents in Europe since the 1970s (the ACCIS project): an epidemiological study. Lancet 364: $2097-2105$

Steliarova-Foucher E, Stiller C, Lacour B, Kaatsch P (2005) International classification of childhood cancer, third edition. Cancer 103: 1457-1467

Stiller CA (1994) Population based survival rates for childhood cancer in Britain, 1980 - 1991. BMJ 309: $1612-1616$

Stiller C (2007) (ed.) Childhood Cancer in Britain: Incidence, Survival, Mortality. Oxford University Press: Oxford

Stiller CA, Bunch KJ (1990) Trends in survival for childhood cancer in Britain diagnosed 1971-1985. Br J Cancer 62: 806-815

Townsend P, Phillimore P, Bebattie A (1988) Health and Deprivation: Inequality and the North. Croom Helm: London

This work is published under the standard license to publish agreement. After 12 months the work will become freely available and the license terms will switch to a Creative Commons Attribution-NonCommercial-Share Alike 3.0 Unported License. 